\title{
Research on the Development of China's Peer-to-Peer Online Lending Industry Based on System Dynamics Simulation
}

\author{
Lingjuan $\mathrm{Xu}^{1}$, Zehua Guan ${ }^{2}$, Lumei Ding ${ }^{1} \&$ Qiucheng Tao ${ }^{1}$ \\ ${ }^{1}$ School of Economics and Management, Nanjing University of Aeronautics and Astronautics, Nanjing, China \\ ${ }^{2}$ School of Banking and Finance, University of International Business and Economics, Beijing, China \\ Correspondence: Lingjuan Xu, School of Economics and Management, Nanjing University of Aeronautics and \\ Astronautics, Nanjing, Jiangsu, 211106, China. Tel: 86-137-7052-2735. E-mail: linda_xu@ nuaa.edu.cn
}

Received: August 24, 2020

Accepted: September 24, 2020

Online Published: October 10, 2020

doi:10.5539/ijef.v12n11p48

URL: https://doi.org/10.5539/ijef.v12n11p48

Funded project: Humanities and Social Sciences Research and Planning Fund of the Ministry of Education (19YJA790098); Science and Technology Innovation Fund for Youth (Humanities and Social Sciences) (NR2017003).

\begin{abstract}
This paper divides the economic operating system of peer-to-peer online lending industry into industry subsystem, investment and financing subsystem and macroeconomic subsystem. By establishing a system dynamics model and conducting simulation analysis, this paper explores the influence and trend characteristics of the monetary policy, regulatory policies and investment and financing expectations to China's P2P industry development. Tight monetary policy promotes the development of the P2P industry in the short term, but it reduces the scale of the industry in the long run. A strong regulatory policy leads to an outbreak of industry risks in the short term and stabilizes the industry in the long run. Changes in investment and financing expectations make the scale experience the process of falling, slight rising to rapid decline. Based on the simulation results, the policy enlightenment and suggestions can be obtained to promote the steady development of $\mathrm{P} 2 \mathrm{P}$ online loan industry.
\end{abstract}

Keywods: P2P online loan, system dynamics simulation, industry development, financial supervision

\section{Introduction}

China's Internet finance industry has developed rapidly in recent years. But the low threshold has led to a mixture of Internet finance companies, among which the P2P online loan industry is the most typical. The P2P platform has the advantages of low threshold, high income, convenient operation, etc. It has promoted social and economic development to a certain extent. But illegal violations such as false bids, capital pools, and fraud in the industry have brought great risks to the financial market. Since 2016, a number of regulatory policies have been promulgated. They have gradually formed the " $1+3$ " regulatory system (One method; three guidelines for filing, custody and information disclosure) for online loans (Jiang, 2019). The strengthening of supervision and the shortage of funds in the financial market have further exposed the internal risks of the P2P platform. According to data from Wangdaizhijia (China's first authoritative third-party online loan information platform), thousands of P2P platforms withdrew and there were 697 problematic platforms in 2018 alone. The survival rate was only $6.1 \%$ in November 2019. Now P2P platforms frequently explode and cause great troubles to investment, financing and regulatory authorities. It is of great practical significance to explore the macro and micro impact factors related to the development of the P2P industry.

Many studies have done in the development and risks of the $\mathrm{P} 2 \mathrm{P}$ online loan industry. $\mathrm{P} 2 \mathrm{P}$ online loan is a financial innovation product combining private lending and Internet. Research has shown that P2P online lending platform has effectively alleviated the financing dilemma of small and medium-sized enterprises and makes better use of idle funds to meet social lending needs (Bachmann et al., 2016; Qian \& Yang, 2012). Daniela et al. (2017) summarized and reviewed the development of financial technology in the international community. They pointed out that this emerging financial service is very important. Shim et al. (2016) used the actor network theory to point out that China's P2P industry has entered the "mobilization" stage since 2014. They emphasized 
the important role of the government. Most of the existing literature analyzes industry risks and puts forward regulatory recommendations from the three levels of the financial and economic environment, the platform itself or investors and borrowers. Puro (2010) analyzed the operating data of the PROSPER platform and found that the higher the credit rating of the borrower, the greater the possibility of obtaining loans. He also pointed out that a higher borrowing interest makes the borrower more likely to get loans. Duarte (2014) believes that the same lender expects different expected return for borrowers of different ages, occupations and races. Yang et al. (2018) have shown that traditional financial market interest rates have extreme risk transmission to online loan market interest rates. Tong et al. (2019) established a binary Logistic regression model to identify the factors of P2P platform credit risk such as the return, dispersion, and liquidity. Borrower risks mainly include credit default risks caused by information asymmetry. The behavior that delay and repayment deliberately using platform crises to to avoid liability is called "reverse run" (Liu \& Mao, 2018; Zhang, Lu, \& Liu, 2018; Zhang \& Huang, 2018; Feng et al., 2017; Li et al., 2014). Zhang et al. (2012) studied the considerations of lenders when lending and concluded that rational investment is better than blindly following others in lending. There is also a significant herd effect among investors, which is very common in the P2P industry (Chen \& Zheng, 2017; Eunkyoung \& Byungate, 2012 ). Tan et al. (2019) used the principal component analysis method to measure the comprehensive value of risk and built a risk warning model based on BP neural network to propose countermeasures. Kevin and Anna (2015) elaborated on the two directions of the risk control plan. On the one hand, government regulators can effectively control financial risks through the supervision of the financial industry. On the other hand, Internet financial companies establish internal risk control systems to effectively avoid financial risks in a timely and effective manner.

As a computer simulation technology, system dynamics has been widely used in various disciplines, especially in the field of economics industry development research. For example, Li et al. (2018) used system dynamics to study the development of China's trust industry and simulated the impact of different industry or monetary policies. There are few article analyzing the development of $\mathrm{P} 2 \mathrm{P}$ online lending industry from the perspective of system dynamics. Tae-heon et al. (2015) established a subsystem and an exploratory system dynamics model of the Korean P2P industry from the perspective of the government, companies, and investors based on interviews But the sample is small and the model needs to be improved. The existing literature has relatively comprehensive research on the P2P network lending. But there are few applications of system dynamics to simulate the P2P network lending industry to explore its development momentum.

The development of the P2P industry is of great significance for improving the utilization rate of idle funds and solving financing difficulties. However, as a relatively new thing, P2P lending platforms are prone to accumulate risks in China's environment that is not yet fully mature, posing a threat tofinancial stability. System dynamics has great advantages in dealing with the problems of high-order, nonlinear and multiple feedback complex time-varying systems. The application of system dynamics simulation method to the development of $\mathrm{P} 2 \mathrm{P}$ lending industry is a meaningful and innovative research. This paper uses this method to study the development of P2P since 2015. It can grasp the financial risks faced by investors, regulators, and industry from a more macro perspective and put forward a proposal for China's P2P financial risk supervision. This new research perspective has certain significance for the financial supervision department to get out of the predicament.

The remainder of the paper is structured as follows. Section 2 analyses the development and main factors of the P2P online lending. Section 3 establishes the system dynamics model. Section 4 conducts an analysis of simulation and model testing. Section 5 concludes the paper.

\section{Analysis of Development and Main Factors of the P2P Online Lending}

\subsection{Overview of P2P Industry Development}

In March 2005, Zopa, the world's first P2P platform, was officially launched in London. Eight companies including Funding Circle, RateSetter, and LendInvest occupy most of the P2P market share in the UK. The P2P industry in the United States regards Lending Club and Prosper as the duopoly market. The P2P online lending development is mainly divided into three stages: start-up, acceptance of supervision, and steady development under supervision. It has basically entered a stable state. At the same time, it is integrating more financial technology factors.

In August 2007, Paipaidai was established in Shanghai as China's first P2P lending platform. The industry has roughly undergone four stages of starting (2007-2011), developing (2012-2013), outbreak (2014-2016), supervision and specification (2016-present) (Bian, 2019). After experiencing explosive growth and frequent thunderstorms, the China's P2P platform is currently in a regulatory transition period. The number of new additions began to drop to 0 and only 400 platforms remain in normal operation in 2019 (Figure 1). Since the rise 
of the P2P industry, there are few platforms that have closed down or transformed in the UK and the United States. For example, only about 16 P2P platforms of UK have exited in recent years (Note 1). The main reason is the difference of regulatory systems. The P2P industries in the UK and the United States have formulated specific and strict management measures. However, China's citizen credit system is not sound and the Internet financial supervision is absent resulting in low costs for law violations. Rapid development of the P2P industry is accompanied by the great risks.

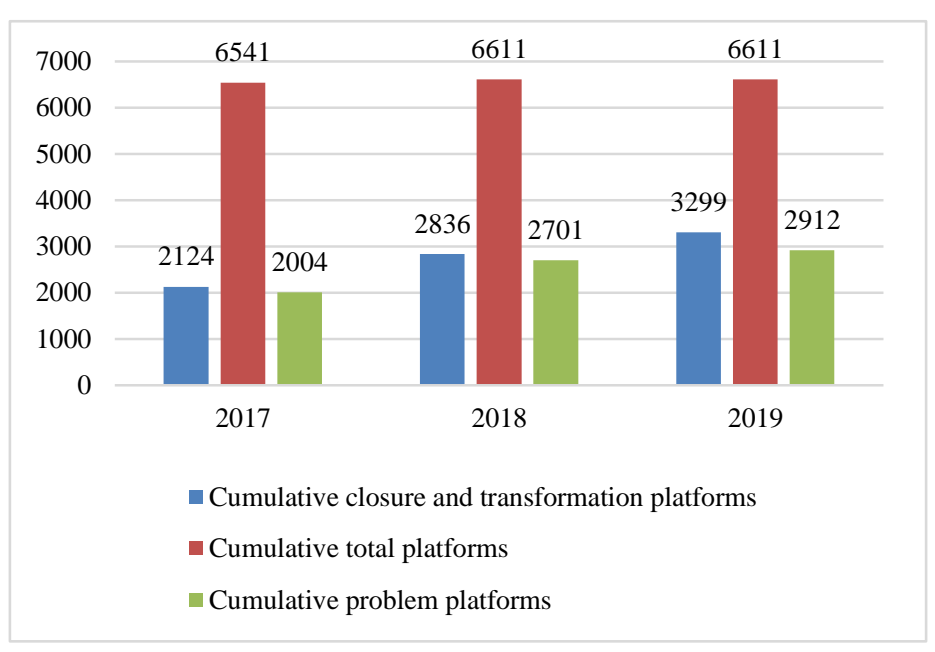

Figure 1. The development of Chian's P2P platform from 2017 to 2019

\subsection{Main Factors Affecting the Development of the P2P Industry}

In order to analyze the internal and external dynamics of the development, this paper constructs the P2P online lending industry system from the industry subsystem, investment and financing subsystem, and macroeconomic subsystem (Figure 2).

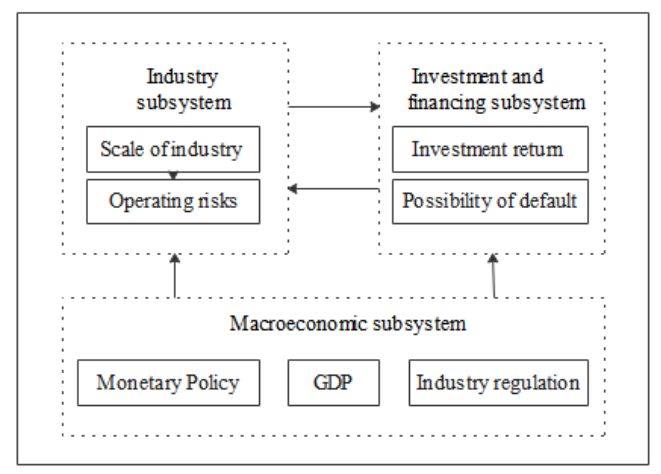

Figure 2. System framework of P2P industry development

\subsubsection{Macroeconomic Factors}

When the central bank adopts a tightening monetary policy, market interest rates will increase significantly. The scale of credit will also shrink which causes financing difficulties for small and medium-sized enterprises (SMEs). However, P2P platforms can alleviate this problem (Cao, 2015). Small and medium-sized enterprises contribute more than $60 \%$ of China's GDP and more than $80 \%$ of urban employment. They are an important economic pillar. Policies that encourage the development of Internet finance have brought opportunities to the P2P lending. Strong government regulatory measures have also made P2P enter the cruel market competition. The main macroeconomic factors include GDP, monetary policy and industry regulatory intensity.

\subsubsection{Investor Factors}

On the one hand, the information on the P2P platforms is relatively transparent. When the returns of P2P industry 
are significantly greater than the stock market or bank, investors tend to P2P. On the other hand, when the P2P industry has risks, investors lose part or all of their principal and will exit (Dong et al., 2017). Investors factors include the investment returns and risk control capabilities.

\subsubsection{Borrower Factors}

Borrowers include both individuals and small and medium-sized enterprises. This article treats them as a whole. When banks tighten credit, small and medium-sized enterprises have difficulty in capital turnover and will turn to P2P lending. At the same time, if SMEs and individuals are unable to repay the loan due, the operating cost of the P2P platforms may increase. Financiers will deliberately postpone the payment if they expect the P2P platform to fail. The factors of financiers include the possibility of default and the demand of capital turnover.

\subsubsection{Industry Internal Factors}

The platform will further expand when its profitability increases. The increase in platform risk has caused some platforms to transform or go bankrupt. At the same time, they will intentionally reduce transaction scale. When the platform acquires new customers, it often means an increase in transaction volume. Direct internal factors include the profitability, risks, and the number of new customers.

\section{Methods}

\subsection{System Dynamics Model and Data}

System dynamics is a scientific method that grasps social, economic and other complex issues from a system perspective combining quantitative and qualitative. It conducts comprehensive research on the macro and micro levels (Wang, 1995). System dynamics has unique advantages when the data is insufficient or difficult to quantify. The collected data is used to perform fitting calculations in order to study system behavior trends and other issues. It is possible to explore the system structure, the causality of relationships and the time evolution of the system. It is very similar to the mechanism in which the financial industry development is driven internally and externally. The data in this article mainly comes from Wangdaizhijia, the National Bureau of Statistics and the CSMAR database, which is monthly from January 2015 to December 2018 (Note 2, Note 3).

Descriptive statistical analysis of important variables used in this paper is performed. The results are shown in Table 1. It can be seen that the average loan term is 9.2 months. Therefore, it is reasonable to use the Shibor of 9 months as a reference, considering the existing research (He \& Peng, 2016).

Table 1. Descriptive statistics

\begin{tabular}{ccccccc}
\hline & M1 & $\begin{array}{c}\text { Average loan } \\
\text { period(month) }\end{array}$ & Return(\%) & $\begin{array}{c}\text { 9M } \\
\text { SHIBOR(\%) }\end{array}$ & $\begin{array}{c}\text { Transacation } \\
\text { volume(billion) }\end{array}$ & $\begin{array}{c}\text { pending } \\
\text { balance(billion) }\end{array}$ \\
\hline Mean & 47276.69 & 9.20 & 10.94 & 3.79 & 208.10 & 1012.02 \\
Median & 48947.53 & 8.69 & 10.05 & 3.53 & 230.60 & 1051.80 \\
Max & 55168.59 & 15.35 & 15.81 & 4.75 & 378.31 & 1833.31 \\
Min & 33638.82 & 6.60 & 9.21 & 2.92 & 35.38 & 112.06 \\
SD & 6743.48 & 2.58 & 1.89 & 0.66 & 96.58 & 564.35 \\
Skewness & -0.60 & 1.08 & 1.20 & 0.15 & -0.14 & -0.10 \\
Kurtosis & 2.00 & 3.12 & 3.17 & 1.43 & 1.90 & 1.70 \\
JB & 4.92 & 9.39 & 11.51 & 5.13 & 2.59 & 3.46 \\
Probability & 0.09 & 0.01 & 0.00 & 0.08 & 0.27 & 0.18 \\
\hline
\end{tabular}

\subsection{The Overall Assumption of System Model}

(1) It is assumed that the larger the scale of the P2P industry development, the stronger the risk control ability. The stricter the government supervision, the stronger the risk control capability of the industry. (2) The number of platforms that explode in the following months is used as a substitute variable for measuring the risk of the P2P platform in this month. (3) The number of investors in the current month is used as a measure of the attractiveness to investors. (4) If a platform has a higher return, the borrower's interest rate will be high. The lending interest and the return are regarded as the same variable. (5) It is assumed that the cost of acquiring new customers on platform is mainly reflected in the return of investment without considering the increase in operating costs due to promotional measures. (6) Regardless of the risk of prepayment, SMEs and individuals are regarded as a whole borrower. 


\subsection{Framework of P2P Industry Development System}

\subsubsection{P2P Industry Subsystem and Loop}

The stronger capacity of controlling risk usually means the higher cost of controlling risk. As the risk weakens, the scale of the industry will increase. The main feedback loop of the internal dynamics causality within the platform is shown as follows.

Loop 1: P2P industry scale $\rightarrow+$ platform risk control capability $\rightarrow$-platform operation risk $\rightarrow-\mathrm{P} 2 \mathrm{P}$ industry scale. The increase in the scale of the P2P industry enhances risk control capabilities, which directly leads to lower risks and attracts more investment. It is conducive to an increase in transaction volume and further expansion of the industry.

Loop 2: P2P industry scale $\rightarrow+$ platform risk control capability $\rightarrow+$ risk control cost $\rightarrow+$ operating cost $\rightarrow$-platform profitability $\rightarrow+$ P2P industry scale. In the negative feedback loop, the increase in the scale means the increase in risk control capabilities and costs, which restricts the profitability of the industry. So the industry scale will decrease.

Loop 3: P2P industry scale $\rightarrow+$ platform risk control capability $\rightarrow+$ risk control cost $\rightarrow+$ operating cost $\rightarrow+$ management fee $\rightarrow+$ platform profitability $\rightarrow+$ P2P industry scale. In a positive feedback loop, the increase of scale will increase the costs of risk control and management costs. But profitability will increase, thereby increasing the scale of the industry.

Loop 4: P2P industry scale $\rightarrow+$ platform risk control capability $\rightarrow+$ risk control cost $\rightarrow+$ operating cost $\rightarrow$-return of investment $\rightarrow+$ acquire new customers $\rightarrow+$ P2P industry scale. Negative feedback loops increase the scale and the cost of risk control. The return is decreased, which reduces the number of new customers and the scale.

\subsubsection{Economic and Environmental Subsystem and Loop}

The expansion of the scale often means that SMEs can obtain more funds. The development of SMEs will affect the P2P industry itself through the economic system. The rapid expansion of scale must arouse the attention of regulatory authorities and also affect the platform itself through different causal paths is shown as follows.

Loop 1: P2P industry scale $\rightarrow+$ SME development $\rightarrow+$ economic growth $\rightarrow+$ personal disposable income $\rightarrow+$ savings-investment $\rightarrow+$ P2P industry scale. Positive feedback loop. The increase of size directly leads to SMEs obtaining financing which is transformed into productivity.

It promotes economic development(increasing GDP), personal disposable income and savings. Partial funds enter the $\mathrm{P} 2 \mathrm{P}$ platform to promote industry development.

Loop 2: P2P industry scale $\rightarrow$-money supply $\rightarrow$-possibility of financier default $\rightarrow$-P2P platform operation risk $\rightarrow+$ national regulatory intensity $\rightarrow+$ operating cost (Note 4 ). As a kind of shadow bank, P2P reduces the currency supply (M1) in the short term (Jiang \& Shen, 2019). This leads to the increase in possibility of borrowers' default resulting in a high risk of the platform and intensity of supervision, which causes more operating costs.

Loop 3: P2P industry scale $\rightarrow+$ national regulatory intensity $\rightarrow$-P2P platform operation risk $\rightarrow$-encourage P2P platform development $\rightarrow$-operating cost. Taking into account the macro-prudential supervision, the increase in transaction volume must attract the attention of financial regulators. National supervision will reduce platform risks, which in turn releases policies that are conducive to the development of $\mathrm{P} 2 \mathrm{P}$ platforms. Thus, P2P operation costs are generally reduced .

\subsubsection{Investment and financing subsystem and loop}

The increase of lending rates increases profitability and promotes the development of the industry. But it also increases the possibility of borrowers' default, which exposes the industry to risks and reduces its scale.

Loop 1: P2P industry scale $\rightarrow+$ platform risk control capability $\rightarrow+$ acquisition of new customers $\rightarrow+$ P2P industry scale. In a positive feedback loop, an increase in the scale will increase the ability to control risk, thus attracting new customers. The scale of industry will expand again .

Loop 2: P2P industry scale $\rightarrow$-money supply $\rightarrow$-financier's possibility of default $\rightarrow$-financier's capital turnover demand $\rightarrow+$ borrowing from P2P $\rightarrow+$ pending balance $\rightarrow+$ financier's possibility of default $\rightarrow+$ platform operation risk $\rightarrow-\mathrm{P} 2 \mathrm{P}$ Industry size. The increase of size will attract a part of funds in the bank, thereby reducing the money supply, which may cause borrowers to default. After capital turnover is eased, they would no longer borrow from P2P. The decrease in the balance reduces the risk and increases the scale. 
Loop 3: P2P industry scale $\rightarrow$-currency supply $\rightarrow$-borrower's possibility of default $\rightarrow+$ borrowing rate $\rightarrow+$ pending balance $\rightarrow+$ financier's possibility of default $\rightarrow+$ platform operation risk $\rightarrow-\mathrm{P} 2 \mathrm{P}$ industry scale. In a negative feedback loop, the increase of scale leads to decrease in the currency supply. The possibility of default increases, which is ultimately not conducive to the expansion of $\mathrm{P} 2 \mathrm{P}$ scale.

Integrating the above three subsystems, the total system causality loop of the P2P industry can be constructed, as shown in Figure 3.

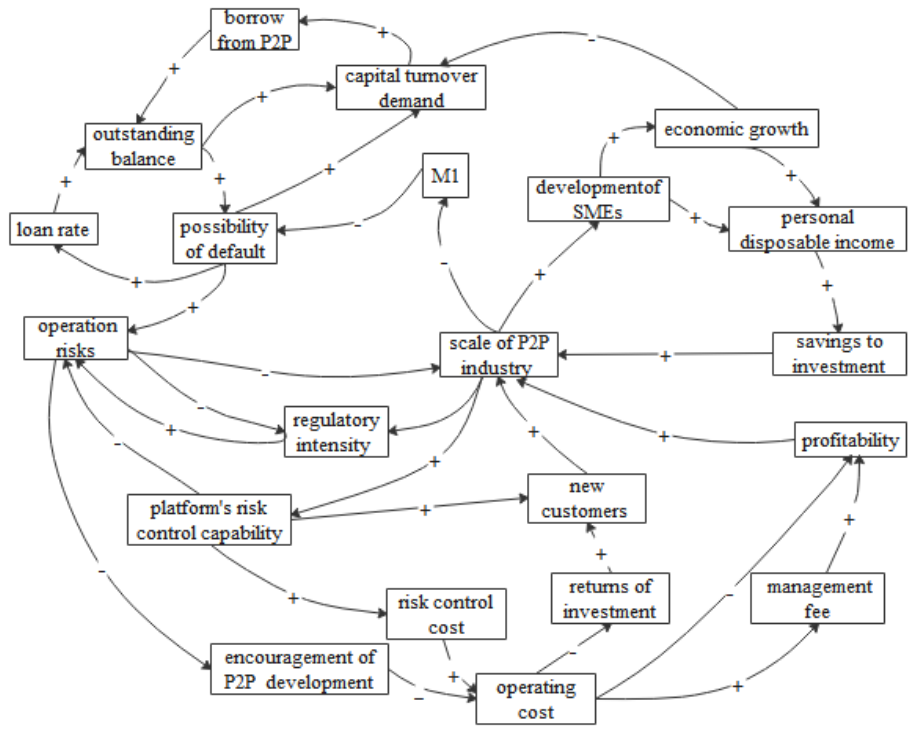

Figure 3. Total system causal loop of P2P industry

\subsection{System Structure Stock Flow Chart}

The causality diagram helps to clarify the relationships between the variables. The stock flow diagram helps to build the quantitative relationship and establish a complex structure mode 1 (Figure 4).

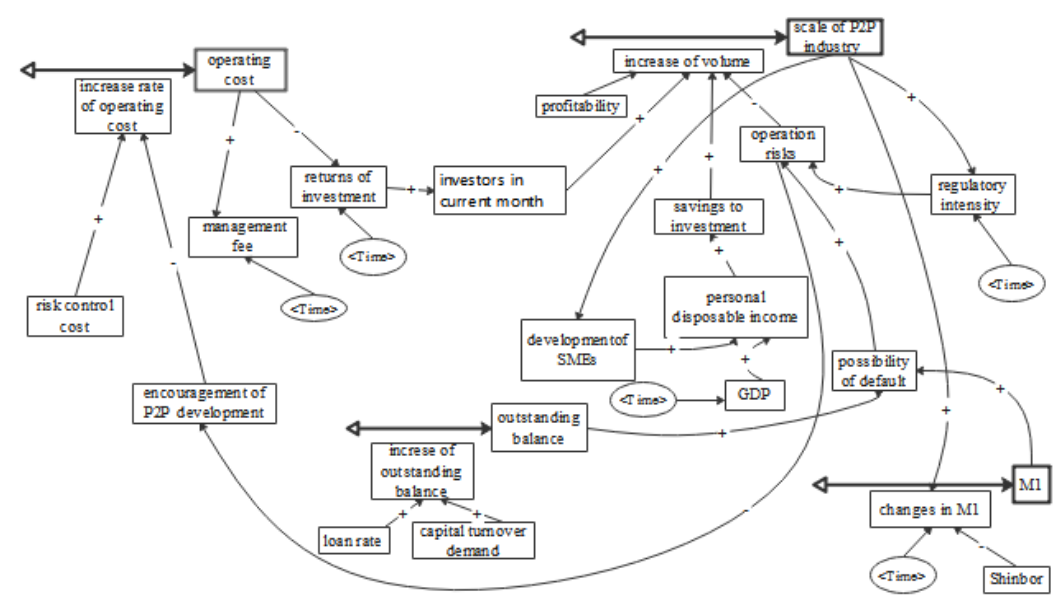

Figure 4. Development system structure stock flow of P2P industry

The values of some variables are replaced by constants. The functional relationship between some variables is obtained by univariate linear regression. And the table function is set to simulate the future changes of each variable.

The main equations are as follows:

INITIAL TIME $=2015$

FINAL TIME $=2025$

TIME STEP $=0.083333$ 
P2P industry scale $=$ INTEG $($ increse of volume, initial value $)$

Currency supply $=($ increse of currency supply, initial value $)$

Balance to be repaid $=$ (increase of balance to be repaid, initial value)

Operating cost $=$ (increase of operating cost, initial value $)$

Industry risk control capability $=$ table function (industry scale, initial value)

Increase of trading volume $=\mathrm{P} 2 \mathrm{P}$ industry scale $*(1+$ profit contribution $*$ elasticity coefficient + investor number contribution of the month *elasticity coefficient+saving-investment contribution * elasticity coefficient operating risk contribution * elasticity coefficient)

\section{Simulation Results}

\subsection{Model Testing}

Verification of System dynamics model can be conducted from three perspectives: intuitive and operational, historical and robustness verification. Through the entire process, continuous verification is required to improve the credibility of the model.

\subsubsection{Intuitive and Operational Verification}

Intuitive verification refers to reading related literature in order to check whether variable settings, feedback loops, system equations, etc. are consistent with the real situation of the system. This article refers to a large number of documents when constructing the system model and uses actual data to fit the development status of the industry. There is no technical error. It can be considered as an intuitive test. In addition, this article tests whether the model has the same dimensions and whether the logical structure is reasonable. Finally, through the Vensim-PLE software, repeated debugging and trend extrapolation of the variable value are conducted to avoid time overflow and numerical overflow. The model can run normally, which can be considered to pass the operational test.

\subsubsection{Historical Verification}

The historical test is to compare the real data of the important stock in the model with the results of the software operation and check whether the relative error is within a reasonable range. This article selects the key variable in the model, namely the P2P industry scale (volume) for testing. The relative error uses $\Delta_{\mathrm{i}}=\left(y_{i}-t_{i}\right) / t_{i}$ for accounting. The historical data of the $\mathrm{i}$-th period is expressed by $t_{i}$. The simulated value of the $\mathrm{i}$-th period is expressed by $y_{i}$. The simulation results of the historical test are shown in Table 1. Considering that the amount of monthly data is too much, quarterly data is used (Note 5).

Generally, when the relative error is within $10 \%$, it can be considered as passing the test. From Table 2, it can be seen that the relative error of the P2P industry scale is basically below $10 \%$ and the average error is within 5\%. It shows that the constructed model is consistent with the reality.

Table 2. Historical test results of P2P industry scale

\begin{tabular}{cccc}
\hline Quarterly & Simulation value(billion) & Actual value(billion) & Relative error(\%) \\
\hline 2015Q1 & 42.23 & 41.68 & 1.3 \\
2015Q2 & 59.17 & 63.72 & -7.2 \\
2015Q3 & 96.84 & 106.67 & -9.2 \\
2015Q4 & 142.37 & 143.40 & -0.7 \\
2016Q1 & 153.35 & 145.27 & 5.6 \\
2016Q2 & 199.30 & 186.77 & 6.7 \\
2016Q3 & 245.77 & 261.14 & -5.9 \\
2016Q4 & 296.14 & 321.62 & -7.9 \\
2017Q1 & 336.80 & 356.24 & -5.5 \\
2017Q2 & 353.18 & 300.25 & 17.6 \\
2017Q3 & 334.50 & 311.10 & 7.5 \\
2017Q4 & 311.49 & 281.20 & 10.8 \\
2018Q1 & 282.07 & 258.65 & 9.1 \\
2018Q2 & 232.14 & 242.35 & -4.2 \\
2018Q3 & 199.92 & 186.67 & 7.1 \\
2018Q4 & 141.60 & 121.42 & 6.6 \\
Mean relative error & & & 2.6 \\
\hline
\end{tabular}




\subsubsection{Robustness Test}

Robustness test is used to test whether the model has better robustness. When using Vensim software for simulation, the initial time step is 1 month and then two months and three months of data are used. It is found that the simulation values are relatively close at different time steps. Variables such as the possibility of default are obtained by regression based on the existing literature and related data. When the values of these variables are changed by $10 \%$, ther key variables have not changed significantly.

\subsection{Scenario Setting and Policy Simulation}

The test results above show that the system can simulate the development of the P2P industry to a certain extent. By setting different scenario changes, this part analyzes the impact on the industry scale and P2P platform risks. The results are shown in Figure 5-8. Run i refers to the data set obtained by changing the relevant parameters of factors. Current refers to the data set obtained from the original simulation. From the scale simulation results, it can be seen that the scale of the P2P industry will rapidly decline in the strong regulatory environment and then increases slowly.

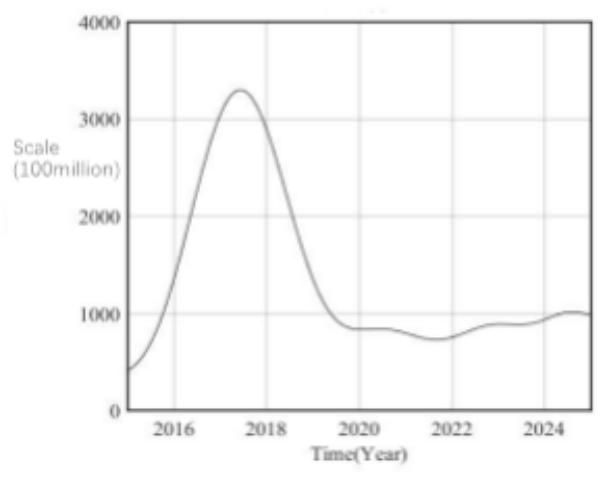

Figure 5. Industry scale simulation result

\subsubsection{Impact of Financial and Economic Policies}

Changing the parameters related to the financial economy can study the impact of economic environment on the scale of the P2P industry and its inherent risks. The main study is the change in monetary policy, that is, the change in credit scale. Taking 2019 as an example, assuming that the M1 increases, Shibor (9M) falls by 30\%. The simulation result is shown in Figure 6. It can be seen that the tightening of credit scale promotes the development of the P2P industry in a short period of time But the scale is declining in the long run. A reasonable explanation is that many SMEs have capital turnover in the short term resulting in lending from the P2P industry. However, when the loans of SMEs expire, more companies will have difficulties in turnover, which adversely affects the industry.

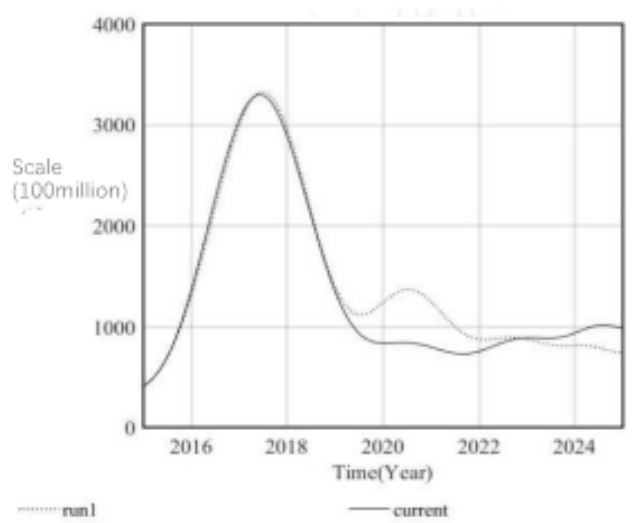

Figure 6. Comparison of tightening monetary policy

\subsubsection{Impact of Industry Regulatory Policies}

From historical data, the supervision of P2P industry will be more stringent. Therefore, this article simulates 
more stringent industry supervision policies and doubles the sensitivity of supervision to the scale. The result is shown in Figure 7. It can be seen that strict industry supervision has a serious impact on the scale in a short period of time and risks explode in advance. With the standardized development of the industry, the transaction volume will increase steadily.

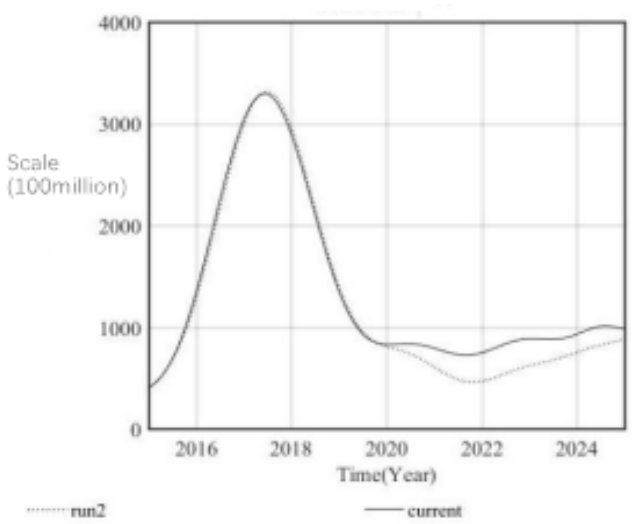

Figure 7. Comparison of strengthening supervision

\subsubsection{Impact of Investment and Financing Expectations}

On the one hand, an increase in the outstanding balance causes borrowers to tend to deliberately postpone payment. Probability of default increases, which increases the coefficient. On the other hand, the proportion of savings converted to P2P platform investment has decreased. Additionally, the number of new investors decreases affected by the investment return. The simulation result is shown in Figure 8 . It can be seen that the transaction volume drops significantly at the beginning. Then the scale increases slightly. And finally the scale declines rapidly. It can be explained that at the beginning many investors are unwilling to invest and the risk increases due to the malicious default. As a result, the scale is reduced and the platform could only respond by increasing the investment return. Therefore, it attracts a part of capital and the scale will further increase. The reduction of scale is due to aggressive operating strategies that leads to a more downturn in the industry.

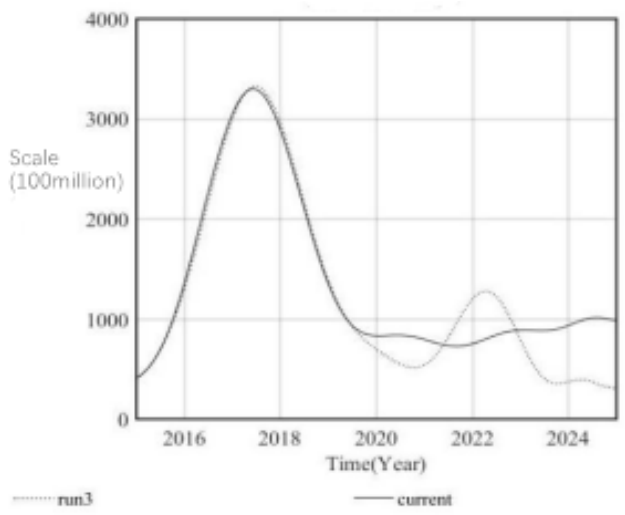

Figure 8. Comparison of investment and financing expectation changes

\section{Conclusion}

Financial freedom and supervision have always been the two main themes in the development of financial theory and practice. As a product of the private lending and the Internet, the P2P platform has its value and significance. To explore the dynamic factors of the growth of $\mathrm{P} 2 \mathrm{P}$ platform and analyze the hidden risks, this paper uses the method of system dynamics to construct a model and simulates the development of the industry under different policies and economic environments. The results are as follows. (a) The strengthening of industry supervision has a significant effect on reducing the risk of P2P platforms. But it also has a huge impact on the scale of the industry in the short term and bring more risks to investors. (b) Changes in the money supply have a more obvious impact on small and medium-sized enterprises. It also significantly increases the risks and reduces the 
scale of P2P platforms. (c) The expectations of investors and borrowers have a huge impact on the P2P platform. The P2P industry has a large decrease in transaction volume at the beginning. Then the scale of increases slightly. Finally the industry scale falls rapidly.

The policy enlightenment and suggestions can be obtained by the results. When raising regulatory requirements, authorities should pay attention to gradual and orderly progress so that Internet finance can develop in a healthy and stable manner. For the healthy development of small and medium-sized enterprises, the central bank's monetary policy tools should not be too large. Additionally, the platform should operate in compliance with regulations and complet bank depository and filing in order to gain the trust of investors and borrowers. Investors and borrowers should fully understand their risks and responsibilities when investing and financing.

\section{References}

Bachmann, A., Becker, A., Buerckner, D. et al. (2011). Online Peer-to-Peer Lending -- A Literature Review. Journal of Internet Banking \& Commerce, 16(2), 1-18.

Cao, F. (2015). Challenge of Internet Finance to Traditional Finance. Finance Forum, 20(01), 3-6+65. https://doi.org/10.16529/j.cnki.11-4613/f.2015.01.002

Chen, D., \& Zheng, H. (2017). Research on Herd Behavior and Decision-making Rationality of China's P2P Online Loan Market. Management Review, 29(01), 3-1. https://doi.org/10.14120/j.cnki.cn11-5057/f.2017.01.001

Dong, J., Wang, G., Sha, S., Miao, J., \& Li, X. (2017). Research on Trust Formation Mechanism of P2P Online Loan Platform. Chinese Journal of Management, 14(10), 1532-1537.

Duarte, J., Siegel, S., \& Young, L. A. (2014). To Lend or Not to Lend: Revealed Attitudes towards Gender, Ethnicity, Weight, and Age in the U.S. SSRN Electronic Journal. https://doi.org/10.2139/ssrn.1573281

Eunkyoung, L., \& Byungtae, L. (2012). Herding behavior in online P2P lending: An empirical investigation. Electronic Commerce Research and Applications, 11(5), 495-50. https://doi.org/10.1016/j.elerap.2012.02.001

Gabor, D., \& Brooks, S. (2017). The digital revolution in financial inclusion: International development in the fintech era. New Political Economy, 22(4), 423-436. https://doi.org/10.1080/13563467.2017.1259298

Ge, R., Feng, J., Gu, B. et al. (2017). Predicting and deterring default with social media information in peer-to-peer lending. Journal of Management Information Systems, 34(2), 401-424. https://doi.org/10.1080/07421222.2017.1334472

He, Q., \& Peng, M. (2016). Research on the Characteristics of Internet Lending Interest Rate Based on Internet Finance. Journal of Financial Research, 10, 95-110.

Jiang, H. (2019). China P2P Lending Service Industry Development Report (2018). Beijing: China Economy Press.

Jiang, S., \& Shen, J. (2019). The Impact of Shadow Banks on China's Money Supply and Economic Growth-Based on the VAR Model. Social Science Research, 06, 24-31.

Jinxin, B. (2019). The status quo, international experience and reference of P2P risk disposal. Southwest Finance, 5, 56-62.

Kevin, E. D., \& Anna, G. (2015). A Legal Reflection on Reform of Internet Finance Tax. International Business and Management, 10, 33-39.

Lee, T. H., \& Kim, H. W. (2015). An exploratory study on fintech industry in Korea: crowdfunding case. $2^{\text {nd }}$ International conference on innovative engineering technologies (ICIET'2015). Bangkok. https://doi.org/10.15242/IIE.E0815045

Li, Y., Gao, J., Li, Z., Cai, Z., Wang, B., \& Yang, Y. (2014). The Impact of Borrower's Descriptive Information on Investor Decisions_—Analysis Based on P2P Network Lending Platform. Economic Research Journal, 49(S1), 143-155.

Li, Z., Zhong, C., Liu, J., Dong, Z., Fang, Y., \& Dong, J. (2018). System Dynamics Simulation Research on the Development of Trust Industry in China. Management Review, 30(04), 3-11. https://doi.org/10.14120/j.cnki.cn11-5057/f.2018.04.001

Liu, H., \& Mao, J. (2018). Research on Outbreak Risk Events of P2P Lending Platforms_— Based on the Perspective of Real Option Theory. Journal of Financial Research, 11, 119-132. 
Puro, L., Teich, J. E., Wallenius, H. et al. (2010). Borrower Decision Aid for People-to-People Lending. Decision Support Systems, 49, 52-60. https://doi.org/10.1016/j.dss.2009.12.009

Qian, J., \& Yang, F. (2012). The development status and prospects of China's P2P network lending. Finance Forum, 17(01), 46-51. https://doi.org/10.16529/j.cnki.11-4613/f.2012.01.008

Shim, Y., \& Shin, D. H. (2016). Analyzing China's fintech industry from the perspective of actor-network theory. Telecommunications Policy, 40(2-3), 168-181. https://doi.org/10.1016/j.telpol.2015.11.005

Tan, T., \& Li, Y. (2019). Research on Risk Early Warning of P2P Lending Platform. Journal of Finance and Economics, 08, 77-83.

Tong, L., Cao, Z., An, L., \& Liang, Q. (2019). Research on Credit Risk Identification of P2P Network Lending $\begin{array}{lllll}\text { Platform. Financial } \quad \text { Theory } & \text { \& } & \text { Practice, } & 10, & \text { 51-58. }\end{array}$ https://doi.org/10.19622/j.cnki.cn36-1005/f.2019.08.013

Wang, Q. (1995). New Advances in System Dynamics Theories and Methods. Application of Systems Engineering Theory and Methods, 2, 6-12.

Yang, W., Lu, L., \& Lin, S. (2018). Research on the Linkage Effect of P2P Online Lending Interest Rate and Traditional Financial Market Interest Rate_Based on the Perspective of Tail Risk Overflow. Financial Economics Research, 33(05), 61-70.

Zhang, H., \& Huang, Y. (2018). Emotions, default rates and reverse runs-Evidence from a mutual gold company. China Economic Quarterly, 17(04), 503-1524. https://doi.org/10.13821/j.cnki.ceq.2018.03.10

Zhang, J., \& Liu, P. (2012). Rational herding in microloan markets. Management Science, 58(5), 892-912. https://doi.org/10.1287/mnsc.1110.1459

Zhang, W., Lu, Y., \& Liu, Y. (2018). Credit risk assessment and application of P2P online loan borrowers based on non-equilibrium fuzzy approximate support vector machines. Systems Engineering-Theory \& Practice, $38(10), 2466-2478$.

\section{Notes}

Note 1. Data is from British P2P Finance Association: British P2P lending market economy Status research report. http://www.199it.com/archives/525717.html.

Note 2. This article uses "volume" as a substitute variable for "scale", and the "platform" data in the table refers to the industry data. The data and definition of "volume" are from Wangdaizhijia. It refers to the total amount of transactions completed on the platform during a certain period of time including bond transfers; excluding novice bids and experience bids.

Note 3. The balance to be repaid refers to the total amount of loan principals have not been repaid by the borrowers, excluding interest and undrawn funds on the account.

Note 4. This does not show a complete loop, in fact, refer to the platform subsystem. In the second loop of the loop, the increase in operating costs will eventually affect the scale of the P2P industry.

Note 5. The model simulation value and actual value are both monthly values. The quarterly data in the table is obtained from the three-month average .

\section{Copyrights}

Copyright for this article is retained by the author(s), with first publication rights granted to the journal.

This is an open-access article distributed under the terms and conditions of the Creative Commons Attribution license (http://creativecommons.org/licenses/by/4.0/). 